\title{
Diet in lung cancer: back to natural and healthy food
}

\author{
Laura D. Ciobanu* \\ Department of Internal Medicine, University of Medicine and Pharmacy “Grigore T Popa”, Iasi, Romania
}

\begin{abstract}
Lung cancer is a complex and multifactorial disease involving genetic, environmental and lifestyle factors. Amongst the latter, nutritional factors are of critical importance, including diet, alcohol consumption, body weight and physical activity. Because of being the most common cancer worldwide in both men and women, preventive measures should be strongly emphasized. The most important risk factor in lung cancer etiology is cigarette smoking, thus preventing the smoking onset and smoking cessation strategies are crucial. Moreover, there are ten nutritional factors to be addressed, like in any other cancer site prevention: alcoholic beverages, overweight and obesity, physical activity, red and processed meat, salt and salted foods, fruits and vegetables, dietary fibers, dairy products, beta-carotene supplements and breastfeeding. People should be more health-conscious, as lean as possible within the normal range of body weight, daily physically active, limit consumption of energy-dense food, of red meat, especially processed meat, salt, and eat mostly foods of plant origin. Avoiding sugary drinks and limiting alcohol intake is strongly advisable. Cancer survivors should follow recommendations for cancer prevention. As proven already, about one third of lung cancer cases are preventable through a healthy, balanced and diversified diet, maintaining a normal weight and practicing regular physical activity.
\end{abstract}

\section{Introduction}

Despite of being a highly preventable disease, lung cancer remains the most common cancer in the world in terms of new cases, 1.8 million in 2012 (12.9\% in total), and mortality [1-3]. It accounts for $19.4 \%$ of all cancer deaths, being the main cancer-related cause of mortality regardless the gender [2]. In both men and women, the incidence of lung cancer is low in young people under 40 years old and increases up to 75-80 years as reported in most populations [4]. This incidence depends on the pattern of smoking in population [4] and on the long period of 20 to 30 years required for lung carcinogenesis to develop [5].

The idea that human diet might influence cancer risk and that appropriate diet could reduce it has opened a new research era, offering new resources for prevention. After two decades of work, researchers have found that the diet-cancer relationship is complex, meeting difficulties in measuring usual diets over time, in estimating nutrients intake at different life stages, together with a long time for cancer to develop. Would it be possible for the diet as a whole to exert a greater influence than the sum of its ingredients [6]? Researchers have found that about a third of the most common cancers are preventable through a nutritious diet, maintaining a healthy weight and regular physical activity [1].

\section{The risky diet and lifestyle}

Lifestyle is a term used to characterize individual behaviors, such as tobacco smoking, alcohol consumption, poor diet and physical inactivity; it implies individual volition to make positive changes [7]. As estimated by Doll and Peto in 1981, cited by White et al [7], 25-40\% of lung cancer-related deaths could be attributed to tobacco use (with a mean of $30 \%$ ), $10-70 \%$ could be attributed to poor diet (with a mean of $35 \%$ ), $4 \%$ to occupation and $2 \%$ to pollution. Nowadays the $35 \%$ estimate of risk attributed to poor diet was replaced by a combination of poor diet or obesity (30\%) and sedentary lifestyle (5\%) [7]. Consistent work of researchers worldwide has focused over the identifiable risk factors in lung cancer and the possibility to influence some of them. Genetic factors, tobacco smoking, diet and alcohol, chronic pulmonary inflammation, ionizing radiation, occupational exposure, environmental pollution (mainly due to tobacco smoke, radon and asbestos), and other risk factors (hormones, underweight) have been largely discussed $[3,5]$. Moreover, the World Cancer Research Fund/ American Institute for Cancer Research Second Expert Report Panel judged that arsenic in drinking water and $\beta$-carotene supplements have increased the risk of lung cancer; but consuming fruits and food containing carotenoids probably has protective consequences [1].

Tobacco smoking is the most avoidable risk factor and it is the main risk factor for all major histological types of lung cancer [3]. Because cigarette smoking accounts for $80 \%$ of the worldwide lung cancer burden in men and at least $50 \%$ of the burden in women, prevention the onset of smoking and successful smoking cessation strategies in current smokers will be the first effective measure in primary prevention of lung cancer $[1,5]$. Not smoking is the first strategy in preventing lung cancer [8].

About $25 \%$ of cancers globally are due to excess weight and to a sedentary lifestyle [9]. Physical activity is defined as any bodily movement produced by skeletal muscle contraction leading to increased energy expenditure above the resting energy expenditure; it is conventionally divided into four types, occupational, transport, recreational and household settings [10]. Regular moderate physical activity is associated with a significantly lower risk of cancer mortality, potentially through improving insulin sensitivity and immune function, and reducing sex hormones, metabolic hormones (e.g. adipokine level), oxidative stress and systemic inflammation [9-11]; it

Correspondence to: Laura D. Ciobanu, Department of Internal Medicine, University of Medicine and Pharmacy "Grigore T Popa", 16 Universitatii Street, 700115 Iasi, Romania, E-mail: laura.ciobanu@umfiasi.ro

Key words: lung cancer, diet, chemoprevention, alcohol, coffee, salt, meat, fruits, vegetables

Received: July 03, 2017; Accepted: July 26, 2017; Published: July 28, 2017 
is recommended a moderate physical activity of 30 minutes daily, with increasing at 60 minutes as fitness improves [1].

Epidemiological evidences suggest an increased lung cancer risk associated with alcohol consumption, especially with beer and liquor, after controlling for cigarette smoking [12]. In addition to ethanol, alcoholic beverages contain antioxidants such as sulfites, flavonoids and resveratrol, as well as chemicals with carcinogenic potential like nitrosamines, asbestos fibers and polycyclic aromatic hydrocarbons [12]. Alcoholic beverages mediate carcinogenesis through multiple mechanisms: pro-carcinogenic effects of acetaldehyde, redox changes, formation of free radicals, liver injury, elevation of sex hormones levels, folate deficiency and interactions with tobacco smoking [10]. Wine may apparently be a protector up to a certain level where its potential antioxidant effects are outweighed by the detrimental effects of high levels of ethanol exposure [12]. Because of the high caloric content of alcoholic beverages, heavy drinkers tend to displace other elements of a diet, having an increased fat intake and eating less fruits and vegetables. The relationship between alcohol and lung cancer has been reported to be stronger or even limited to individuals who eat less vegetables, vitamin A and carotenoids [12].

A meta-analysis published in 2011 [13] reported no association between alcohol consumption and lung cancer risk in never smokers; seemingly, alcohol does not play an independent role in lung cancer etiology in this category of people. Authors cannot conclude that alcohol is not associated with lung cancer in smokers [13]; alcohol may enhance the carcinogenic effect of cigarette smoke on lung tissue by inducing the activity of cytochrome P-450 enzymes, which in turn can activate procarcinogens present in alcoholic beverages $[13,14]$. The relation between lung cancer and alcohol is difficult to interpret due to the confounding effect of smoking, and because lung cancer is not a homogenous disease [13]. Experimental studies have shown that alcohol acts in the later stages of carcinogenesis as a co-carcinogenic or promoter, and not as an initiator [14]. It is therefore recommended to limit alcohol consumption to no more than two drinks a day in men and one drink a day in women [1].

A limited number of studies have proven that coffee drinkers had a higher risk for lung cancer, but they are far more likely to smoke than non-drinkers; these results are debatable if considering the chemopreventive mechanisms of action of some coffee components. Guertin et al. [15] found that coffee drinking was positively associated with lung cancer, although the association is obviously attenuated after adjustment for tobacco smoking; drinkers of more than 6 cups a day have a hazard of $30 \%$ comparing to non-drinkers. Coffee drinkers are more likely to be men, smokers, and to have a low level of education. Greater smoking intensity was strongly correlated with heavier coffee consumption, probably through the shared CYP1A2 metabolic pathway [15]. Most coffee consumed in the USA is filtered coffee, so these findings reflect the association between coffee filtered and lung cancer; it is possible that associations may differ for other types of coffee (unfiltered, percolated, espresso) due to different proportion of caffeine and other constituents [15]. A meta-analysis conducted by Tang et al. [16] indicated that high or an increased consumption of coffee more than two cups a day may increase the risk of lung cancer, but there is an opposite effect in non-smokers and in decaffeinated coffee users. Because of residual confounding effects of smoking and other factors, these results should be interpreted with caution [16].

As demonstrated by Sinha et al. [17], consumption of red meat, mainly fried and/or well-done, was associated with an increased risk of lung cancer, most probably due to the formation of heterocyclic amines during cooking at high temperatures, especially by pan-frying and grilling [18]. The effect on cancer might be linked to mutagenic compounds generated in red meat and processed meat such as heterocyclic amines, polycyclic aromatic hydrocarbons and N-nitroso compounds [10]. Among heterocyclic amines, only 2-amino-3,8dimethylimidazol[4,5-f]quinoxaline (MeIQx) was associated with increased risk for lung cancer in nonsmokers and in light/moderate smokers, but not in heavy smokers [18]; cigarette smoking is a major risk factor for lung cancer that is probably overwhelming the risk associated with MelQx. There is also evidence issued from animal carcinogenesis studies that MelQx may be a lung carcinogen. There was reported an elevated risk with MelQx intake for subjects with squamous cell carcinomas and "other histological cell types", but not for subjects with small cell carcinomas and adenocarcinomas [18].

As reported by Okubo et al. [19], processed meat consumption was negatively associated with the lung function in both males and females; it was a stronger association among males with low fruit and vegetable consumption, low dietary total antioxidant capacity and current smoking. Men and women with a high consumption of processed meat, participants at the European Prospective Investigation into Cancer and Nutrition (EPIC) study, followed-up for a median time of 12.7 years, with a maximum of 17.8 years, were at increased risk of death, especially due to cardiovascular diseases and cancer [20]. If processed meat intake would be reduced at less than $20 \mathrm{~g} /$ day, this action would prevent $3.3 \%$ of all deaths [20].

Processed meat (i.e., bacon, gammon, ham, corned beef, spam and luncheon meal, sausages and meat pies) is associated with a worse lung function in both males and females [19]. Processed meat is treated by salting, curing, smoking, has added nitrites as preservatives, antimicrobial agents, taste improvers and color fixatives [19] [20] [21]. Dietary nitrites generate reactive nitrogen species that amplify inflammatory processes in the lung parenchyma and airways, leading to DNA damage, inhibition of mitochondrial respiration, protein dysfunction and cell damage through oxidative and nitrosative damage [19]. Processed meat is also rich in advanced glycation endproducts, which can increase oxidative stress and inflammation [19]. As meat intake is a modifiable risk factor, a healthy diet should contain a low, still not a zero daily amount, as it is an important source of proteins, iron, zinc, vitamins $\mathrm{A}$ and $\mathrm{B}$, and essential fatty acids (linoleic, eicosapentaenoic and docosahexaenoic acids) [20] [21]. Meat consumption should be, as a population target, not more than $300 \mathrm{~g}$ red meat per capita per week, while the personal target for meat-eaters should be less than $500 \mathrm{~g}$ red meat per week, very little, if any of which, to be processed [1].

A pooled analysis on eight prospective cohort studies could not identify any statistically significant association between intakes of total or specific types of dietary fat (saturated, monounsaturated or polyunsaturated) and lung cancer among never, past and current smokers, in both males and females. Dietary cholesterol was not associated with lung cancer risk in a multivariate analysis made by Smith-Warner et al. [22].

According to WCRF/AICR 2007 [1], the population average consumption of salt from all sources should be less than $5 \mathrm{~g}(2 \mathrm{~g}$ of sodium) a day. Experimental and in vivo data have shown that a high intake of salt is a risk factor for acute lung inflammation and edema, and acts through $\mathrm{M}(\mathrm{Na})$, a novel macrophage activation state saltinduced [23]. 
There are important debates around $\boldsymbol{\beta}$-carotene supplements, an antioxidant naturally present in many fruits and vegetables and designated by the US Food and Drug Administration as "generally recognized as safe" to be used as a dietary supplement and as an additive in foods [24]. $\beta$-carotene has been the subject to one of the most intensive chemoprevention research, but there have been registered important differences in results between observational studies and preventive trials [3]. The incidence of lung cancer among former and current smokers, as well in workers exposed to asbestos, has increased in two pilot studies began in 1985: the $\alpha$-Tocopherol, $\beta$-Carotene Cancer Prevention Study (ATBC) and the $\beta$-Carotene and Retinol Efficacy Trial (CARET). They have been described some limitations of the studies that make the results questionable: it has been used a synthetic $\beta$-carotene, composed almost entirely of transisomeric $\beta$-carotene (but they are no more than 272 geometrical isomers synthesized commercially and difficult to be all assessed for their influence over health); the dose of $\beta$-carotene used in the trials was five to ten times the normal dietary intake; the possibility that these high doses of $\beta$-carotene generating supra-physiologic serum concentrations might inhibit the absorption of other dietary carotenoids and antioxidants with cancer-protective properties; confounding factors in fruits and vegetables other than $\beta$-carotene; an underestimation of maximum achievable effects of treatment due to the limited follow-up duration of 4-6 years; lack of information of dietary habits earlier in life; the possibility that antioxidant carotenoids cause oxidative stress through pro-oxidant activity, depending on the redox potential and biological environment; and finally the possibility that $\beta$-carotene have co-carcinogenic effects by boosting the activity of the phase I enzymes that bioactivate tobacco smoke precarcinogens like polycyclic aromatic hydrocarbons [3] [24] [25] [26].

The expert panel of the 2007 WCRF/AICR Second Report concluded as convincing evidence that high doses of $\beta$-carotene supplements (in smokers) increase the risk of lung cancer; fruits and foods containing carotenoids probably decrease the risk of lung cancer [1]. While high-dose supplements of $\beta$-carotene have increased the lung cancer risk in male smokers due to aberrant cell growth in the respiratory epithelium [27], such finding does not exclude that a diet based on fruits, non-starchy vegetables and pulses (legumes), with a high content in vitamins, antioxidants and phytonutrients apart from $\beta$-carotene, in more balanced doses, may benefit in reducing lung cancer risk [8]. An illustrative example comes from a systematic review over the cruciferous vegetable (rich in isothiocyanates, like broccoli, cabbage and others) consumption and lung cancer risk conducted by Lam et al [28]. The authors found a weak and inverse association between cruciferous intake and the risk of lung cancer, stronger for the homozygous deletion for GSTM1 and GSTT1, some variants of Glutathione S-transferases (GST) genes [28].

When assessing the role of dietary supplements, it should be taken into consideration the observation made by Forman and Altman that "the effect on disease with long latency periods of pharmacological doses of specific micronutrients over a few years in middle-aged adults is a different scenario from physiological doses of the same micronutrients provided as part of a balanced diet on a lifelong basis, starting in childhood" [29]. For cancer prevention, people should not rely on dietary supplements, excepting severe illnesses or dietary inadequacy, where supplements might be valuable [1].

\section{Chemoprevention in lung cancer}

Chemoprevention means the use of specific agents to reverse, suppress or prevent the process of carcinogenesis; the goal is to reduce disease incidence and mortality. It involves the use of dietary or pharmaceutical interventions to slow or reverse the progression of premalignancy to invasive cancer [5]. Natural products originated in marine and terrestrial organisms feature numerous chemical structures that modulate a wide range of biological effects. They have been used in traditional medicine for thousands of years without having a complete understanding of their mechanism of action [30]. Phytochemicals or phytonutrients are bioactive food constituents derived from a plant source; they intervene as inducers of important mechanisms related to antioxidant defense, longevity, cell maintenance, gene expression modulation and DNA repair [31]. Plant-based food introduces significantly more antioxidants into human diet than non-plant food based on meat, fish and other products originated from the animal kingdom. There is no linear relationship between the antioxidant content of a food sample and the antioxidant activity in the target cell; the bioavailability of the antioxidants depends on the food matrix, absorption through action of gut microbiota and metabolism [31].

Thousands of fruits and vegetables constituents manifest protective effects mainly by reducing oxidative damage of DNA, increasing the activity of enzymes able to detoxify carcinogens, stimulation of immunologic response, modulation of hormonal level and antiproliferative activities [25] [26]. Because of the overwhelming confounding effect of smoking, the true relationship between fruits, vegetables and lung cancer might be better clarified by studying a never smoking population, but lung cancer is a rare disease in never smoking people and data gathered so far are insufficient to draw a sound conclusion [25]. Tens of case-control and cohort studies conducted over many years in various populations have indicated that people who eat more vegetables and fruits, food rich in $\beta$-carotene and carotenoids, and those with higher blood $\beta$-carotene concentrations, have a lower risk of lung cancer [32]. A recent meta-analysis from 2016 has concluded that the current evidence from prospective studies is consistent with a protective role of fruits and vegetables in lung cancer etiology [8]. A healthy diet with plenty of whole grains, pulses (legumes), non-starchy vegetables and fruits, with a high content in vitamins, antioxidants and phytonutrients apart from $\beta$-carotene, in balanced doses, may benefit in reducing lung cancer risk [8]. Significant inverse dose-response associations were observed for each increase of $100 \mathrm{~g} /$ day for fruits and vegetables. The risk for lung cancer decreases by $27 \%$ with increasing intake up to $400 \mathrm{~g} /$ day; no benefit was obtained with increasing consumption above $400 \mathrm{~g}$, which mean 5 portions per day [8]. The population average consumption of non-starchy vegetables and of fruits should be at least $600 \mathrm{~g}$ daily; the personal intake should be at least $400 \mathrm{~g}$ or five portions a day of non-starchy vegetables and fruits [1].

A cup of coffee is a complex mixture containing more than a thousand molecules, heterogeneous bioactive compounds able to act on different cancer hallmarks, helping to prevent its appearance and development [30]. It has been demonstrated that daily drinking of 4-6 cups of regular black coffee, meaning up to $750 \mathrm{~mL}$, is sufficient to prevent carcinogenesis and slow the progression of different types of cancer [33]. The current body of evidence recommends coffee consumption to be included into a healthy lifestyle [30].

Green tea, with its high level of flavonoids, has strong chemopreventive effects against lung tumorigenesis in most animal studies through multiple mechanisms, especially by inducing cell cycle arrest and apoptosis. Still, epidemiological studies on the cancerpreventive effects of tea have produced inconsistent results [34]. Whereas majority of studies have focused over antineoplastic effects of 
green tea, the potential health benefits of white tea become increasingly recognized [5]. Mao et al. [35] have found that the white tea extract is capable of inducing apoptosis in non-small cell lung cancer (NSCLC) cell lines through up-regulation of the peroxisome proliferatoractivated receptor-gamma and 15-lipoxygenase signaling pathways, with enhanced activation of caspase 3 that plays a central role in the execution-phase of cell apoptosis. White tea extract should be furtherly investigated as an antineoplastic and chemopreventive agent for lung cancer [35].

Dietary fibers intake might be beneficial in smoking-related lung diseases as COPD and lung cancer, where systemic inflammation is highly prevalent and linked to poor outcomes [36]. Dietary fibers are not absorbed in the small intestine; they exert a protective effect in several cancers through prevention of insulin-resistance, decrease of insulinlike growth factor-1, decrease systemic inflammation via production colonic microbiota reinforcing the intestinal barrier [10]. Short-chain fatty acids have anti-inflammatory (by inhibition of 3-hydroxy-3methylglutaryl-coenzyme A reductase antiproliferative and proapoptosis effects [10]. High fiber intake might partly explain the lower rates of COPD and lung cancer in Mexican (the Hispanic paradox) legumes, mainly beans, lentils and soybeans products respectively [37]. The daily intake of soluble and insoluble fibers originating in fruits, vegetables and cereals should be over $25 \mathrm{~g}$ [10].

Dairy products comprise milk (whole or skim), cheese (fresh, cottage and hard cheese) and yoghurt. They can have positive and negative effects on carcinogenesis in the same time, so the level of evidence concerning lung cancer is not conclusive [10]. The possible protective effect acts through the calcium content and to a lesser extent through vitamin $\mathrm{D}$, lactoferrin and fermentation products; new data concluded that dairy products can modulate inflammatory processes. Milk is a source of cholesterol and saturated fatty acids that might increase cancer risk, but it also contains conjugated linoleic acid, sphingolipids and butyric acid, with hypolipidemic and antioxidant properties [10].

Experimental studies have observed that vitamin D inhibits metastasis, angiogenesis and lung carcinoma progression [11], while higher vitamin D receptor expression in lung tumors is associated with improved survival through lower proliferative status and G1 arrest [38]. Still, higher serum concentration of 25-hydroxyvitamin $\mathrm{D}(25(\mathrm{OH}) \mathrm{D})$ and vitamin $\mathrm{D}$ binding protein did not influence lung cancer survival in a population of male smokers; moreover, Taql polymorphism of vitamin $\mathrm{D}$ receptor gene appears to be a risk factor for lung cancer [39]. Although there is no overall association between 25(OH)D level and lung cancer risk, Kilkkinen et al. [40] have observed that women and younger participants with higher serum levels of $25(\mathrm{OH}) \mathrm{D}$ have a lower risk for lung cancer. Vitamin $\mathrm{D}$ has two origins in humans, nutrition and photosynthesis in the skin when exposed to ultraviolet B radiation; Weinstein et al. [41] have found an inverse association between $25(\mathrm{OH}) \mathrm{D}$ status and lung cancer risk when blood was collected during the darker months of the year November-April, a time when skin synthesis of vitamin $\mathrm{D}$ is reduced. The ability of 1,25 dihydroxycholecalciferol (or calcitriol) to induce cell cycle arrest, apoptosis and differentiation at doses without toxicity makes it an attractive lung cancer chemopreventive agent [5].

Even if difficult to believe, but breastfeeding has protective effects in cancer prevention in both mother and child. The World Health Organization recommends exclusive breastfeeding up to 6 months of of short-chain fatty acids by gut microbiota, and optimization of the and Asian population, with a traditionally increased consumption of

age, and to continue it up to two years of age or beyond in parallel with a diversified diet [1]. For recommendations from above, see table 1.

\section{Other dietary sources in chemoprevention of lung cancer}

Non-toxic phytochemicals found abundantly in vegetables, fruits and herbs have become a very promising source of potential anticancer agents and new chemotherapy adjuvants. They have been shown to induce apoptosis in cancer cells and inhibition of tumor growth both in vitro and in vivo. Phytochemicals can block cancer initiation through antioxidative/anti-inflammatory pathways, induce apoptosis/cell cycle arrest/autophagy in pre-initiated/initiated tumor cells, and might block tumor progression and metastasis in more advanced tumors [42]. These things are proven nowadays for carotenoids, alkaloids, polyphenols (e.g. resveratrol), isoflavones from soy, vitamin D3, just to mention only few of them [42]. Future studies should focus on the most appropriate phytochemical, combination and dose for each type of tumor.

Curcumin, a yellow spice that enters in the composition of curry, is a polyphenolic molecule extracted from the rhizome of the plant Curcuma longa. Used for thousands of years in Ayurvedic, Chinese and Hindu traditional medicine, it is considered nowadays as a promising chemopreventive compound able to reverse, inhibit or prevent the development of cancer by inhibiting the molecular signaling pathways involved in carcinogenesis [43]. The chemopreventive effect is mainly based on the ability to decrease cancer cell proliferation through disruption of the cell cycle and death of cell by apoptosis, mitotic catastrophe and autophagy; the antiproliferative effect was observed

Table 1. Diet recommendations for lung cancer prevention based on World Cancer Research Fund/American Institute for Cancer Research WCRF/AICR 2007 [1] and other specific studies $[8,10,19,20,33,50]$

\begin{tabular}{|c|c|c|}
\hline Substance & Recommendation & Observation \\
\hline $\begin{array}{l}\text { Breastfeeding (mother's } \\
\text { milk) }\end{array}$ & At least for 6 months of age & $\begin{array}{l}\text { Protective against any } \\
\text { cancer for both mother and } \\
\text { child }\end{array}$ \\
\hline Water & $\begin{array}{l}\text { Approximately } 2 \mathrm{~L} / \text { day (at } \\
\text { least } 20 \mathrm{~mL} / \text { per kilo weight) }\end{array}$ & $\begin{array}{l}\text { Advisable still, alkaline, } \\
\text { spring-originated water }\end{array}$ \\
\hline Body weight & As lean as possible & $\begin{array}{l}\text { Avoid increase in waist } \\
\text { circumference while aging; } \\
\text { look for nutritional advice }\end{array}$ \\
\hline Physical activity & $>30$ minutes/day & $\begin{array}{l}\text { Outside the house (at least } \\
\text { brisk walking) or inside } \\
\text { (house holding) }\end{array}$ \\
\hline Tobacco smoking & No smoking & $\begin{array}{l}\text { Avoid starting or seek for } \\
\text { smoking cessation strategies }\end{array}$ \\
\hline Coffee & $\begin{array}{l}<4-6 \text { cups/day of regular } \\
\text { black coffee }\end{array}$ & No sugar and/or milk added \\
\hline Alcohol intake & $\begin{array}{l}<2 \text { drinks/day in men, }<1 \\
\text { drink/day in women }\end{array}$ & $\begin{array}{l}\text { Less spirits in men, less beer } \\
\text { in women }\end{array}$ \\
\hline Salt & $<5$ g/day & $\begin{array}{l}\text { Use other methods but } \\
\text { salting to preserve food: } \\
\text { refrigeration, freezing, } \\
\text { drying, bottling, canning or } \\
\text { fermentation }\end{array}$ \\
\hline Meat & $<300 \mathrm{~g} /$ capita/week & $\begin{array}{l}\text { Reduce red and especially } \\
\text { processed meat; reduce } \\
\text { dietary fat of animal origins }\end{array}$ \\
\hline Fruits and vegetables & $>400 \mathrm{~g} /$ day, $>5$ portions/day & $\begin{array}{l}\text { Mainly fresh and of different } \\
\text { colors: red, green, yellow, } \\
\text { white, purple and orange }\end{array}$ \\
\hline Dietary fibers & $>25 \mathrm{~g} /$ day & $\begin{array}{l}\text { From fruits, vegetables, and } \\
\text { unprocessed cereals }\end{array}$ \\
\hline Dairy products & $\begin{array}{l}\text { Not conclusive for cancer } \\
\text { prevention }\end{array}$ & $\begin{array}{l}\text { Both positive and negative } \\
\text { effects in lung cancer } \\
\text { genesis }\end{array}$ \\
\hline
\end{tabular}


in several cancer cell types (lung, prostate, breast, head and neck, lymphoma and leukemia) [43].

Ginger (Zingiber officinale), a common condiment, has long been used in oriental medicine for the anti-inflammatory and chemopreventive activities of its major pungent constituents including gingerols, shogaols and paradols. These ginger polyphenols have been attributed with anticancer effects through antioxidant, antiinflammatory, antiproliferative, antiangiogenic, anti-invasive and antimetastatic activities. [6]-Shogaol seems to be the most potential candidate for the prevention and treatment of NSCLC. Shogaol suppresses the proliferation of NSCLC cells by inducing cycle arrest (G1 and G2/M) and apoptosis [44]. Despite being more common and spreading more slowly than SCLC, most of NSCLC are diagnosed only when the cancer has metastasized; also, primary and secondary resistance limits therapeutic success. Adopting appropriate preventing strategies might reduce the incidence and mortality from NSCLC [44].

Seaweeds are very rich in beneficial bioactive compounds like proteins, carbohydrates, lipids and fatty acids, polysaccharides, phenols, phytosterols, antioxidants, minerals, vitamins and dietary fibers. Marina algae have a high content in polyunsaturated fatty acids (PUFAs), especially in a-linoleic, octadecatetraenoic, arachidonic and eicosapentaenoic acids, playing an important role in the prevention of cardiovascular disease, osteoarthritis, and diabetes; they also exhibit antiviral, antimicrobial, anti-inflammatory and antitumoral properties [45]. Monogalactosyldiacylglycerols (MGDG) and digalactosyldiglycerols (DGDG), the major glycolipids from Ulva armoricana and Solieria chordalis, were shown to inhibit in vitro the growth of NSCLC-N6 cell lines derived from a human NSCLC [45].

Maslinic acid (MA) is a pentacyclic triterpenic acid naturally occurring in many plant foods such as hawthorn fruit, basil, brown mustard and olive. Treatment with MA caused A549 cells apoptosis via mediating mitochondrial apoptoic pathway and HIF-1 $\alpha$ pathway under normoxic and hypoxic conditions. These findings support that MA is a potent agent against lung cancer (A549 - a lung adenocarcinoma cell line; HIF-1 $\alpha$ - hypoxic inducible factor-1 $\alpha$ ) [46].

Siberian ginseng (Eleutherococcus senticosus) used in herbal Western medicine as tea or roots extract for its immune stimulant properties, also displays anti-cancer properties. These may affect tumor growth and provide an anti-fatigue effect for cancer patients, in particular for those suffering from lung cancer. The anti-carcinogenic, anti-inflammatory and anti-oxidant activity of Eleutherococcus senticosus and Acanthopanax senticosus used in East Asian medicine are seen in cell cultures, animal studies and even in humans [47].

Perilla frutescens Britton leaves are a commonly consumed vegetable in different Asian countries. Ethanol extract of Perilla leaf (PLE) have been shown to inhibit growth, anchorage-independent colony formation, adhesion and migration in human lung cancer cells, indicating the anti-cancer of PLE in vitro [48].

Due to its bioavailability and acceptable toxicity, valeric acid (2-propylpentanoic acid), a short chain fatty acid extracted from Valeriana officinalis roots (used for more than 2000 years in traditional medicine as tea or tincture) has become one of the most promising compounds for cancer prevention and treatment. They are already ongoing clinical trials in phase I or II using 2-propylpentanoic acid in combination with Camptothecin, Irinotecan, Karenitecin, Doxorubicine, Vindesine (targeting topoisomerase inhibitors), and with azacitidine and decitabine also (targeting DNA methyltransferase inhibitors) for the treatment of lung cancer [49].

\section{Conclusion}

There is a recent strong call to return to nature in all activities, in eating, acting and thinking. Throughout a great generosity, nature makes available to humanity an almost endless pool of plant-based food, very potent in prevention and/or treating chronic diseases, including cancer. And because human body is made of water in a proportion of 70 percent, people should me more cautious to the water quality and daily amount to drink, and to continuously express feelings of love and gratefulness, as we are so well advised by the Japanese researcher Masaru Emoto [50].

\section{References}

1. World Cancer Research Fund/American Institute for Cancer Research WCRF/ AICR 2007. Food, nutrition, physical activity and the prevention of cancer: a global perspective. Washington DC: AICR; Date last accessed: February 252017.

2. Schild SE, Vokes EE (2016) Pathways to improving combined modality therapy for stage III nonsmall-cell lung cancer. Ann Oncol 27: 590-599. [Crossref]

3. Malhotra J, Malvezzi M, Negri E, La Vecchia C, Boffetta P (2016) Risk factors for lung cancer worldwide. Eur Respir J 48: 889-902. [Crossref]

4. Malvezzi M, Bosetti C, Rosso T, Bertuccio P, Chatenoud L, et al. (2013) Lung cancer mortality in European men: trends and predictions. Lung Cancer 80: 138-145. [Crossref]

5. Szabo E, Mao JT, Lam S, Reid ME, Keith RL. (2013) Chemoprevention of lung cancer. Diagnosis and management of lung cancer, 3rd ed: American College of Chest Physicians evidence-based clinical practice guidelines. Chest 143 (Suppl): e40S-e60S. [Crossref]

6. McMichael AJ (2008) Food, nutrition, physical activity and cancer prevention Authoritative report from World Cancer Research Fund provides global update. Public Health Nutr; 11: 762-763. [Crossref]

7. White MC, Peipins LA, Watson M, Katrina F. Trivers, Dawn M. Holman, et al. (2013) Cancer prevention for the next generation. J Adolesc Health 52: S1-S7. [Crossref]

8. Vieira AR, Abar L, Vingeliene S, Chan DS, Aune D, et al. (2016) Fruits, vegetables and lung cancer risk: a systematic review and meta-analysis. Ann Oncol 27: 81-96. [Crossref]

9. McTiernan A (2008) Mechanisms linking physical activity with cancer. Nat Rev Cancer 8: 205-211. [Crossref]

10. Latino-Martel P, Cottet V, Druesne-Pecollo N, Pierre FH, Touillaud M ,et al. Alcoholic beverages, obesity, physical activity and other nutritional factors, and cancer risk: a review of the evidence. Crit Rev Oncol Hematol 2016; 99: 308-323. [Crossref]

11. Anic GM, Weinstein SJ, Mondul AM, Männistö S, Albanes D (2014) Serum vitamin D, vitamin D binding protein, and lung cancer survival. Lung Cancer 86: 297-303. [Crossref]

12. Bandera EV, Freudenheim JL, Vena JE (2001) Alcohol consumption and lung cancer. A review of the epidemiological evidence. Cancer Epidemiol Biomarkers Prev 10: 813821. [Crossref]

13. Bagnardi V, Rota M, Botteri E, Scotti L, Jenab M, et al. (2011) Alcohol consumption and lung cancer risk in never smokers: a meta-analysis. Ann Oncol 22: 2631-2639. [Crossref]

14. Pöschl G, Seitz HK (2004) Alcohol and cancer. Alcohol Alcohol 39: 155-165. [Crossref]

15. Guertin KA, Freedman ND, Loftfield E, Graubard BI, Caporaso NE, et al. (2016) Coffee consumption and incidence of lung cancer in the NIH-AARP Diet and Health Study. Int J Epidemiol 45: 929-939. [Crossref]

16. Tang N, Wu Y, Ma J, Wang B, Yu R (2010) Coffee consumption and risk of lung cancer: a meta-analysis. Lung Cancer 67: 17-22. [Crossref]

17. Sinha R, Kulldorff M, Curtin J, Brown CC, Alavanja MC, et al. (1998) Fried, well-done red meat and risk of lung cancer in women (United States). Cancer Causes Control 9: 621-630. [Crossref]

18. Sinha R, Kulldorff M, Swanson CA, Curtin J, Brownson RC, et al. (2000) Dietary heterocyclic amines and the risk of lung cancer among Missouri women. Cancer Res 60: 3753-3756. [Crossref]

19. Okubo H, Shaheen SO, Ntani G, Jameson KA, Syddall HE, et al. (2014) Processed meat consumption and lung function: modification by antioxidants and smoking. Eur Respir J 43: 972-982. [Crossref] 
20. Rohrmann S, Overvad K, Bas Bueno-de-Mesquita H, Jakobsen MU, Egeberg R, et al. (2013) Meat consumption and mortality - results from the European Prospective Investigation into Cancer and Nutrition. BMC Med 11: 63. [Crossref]

21. Varraso R, Camargo CA Jr (2014) Processed meat consumption and lung health: more evidence for harm. Eur Respir J 43: 943-946. [Crossref]

22. Smith-Warner SA, Ritz J, Hunter DJ, Albanes D, Beeson WL, et al. (2002) Dietary fat and risk of lung cancer in a pooled analysis of prospective studies. Cancer Epidemiol Biomarkers Prev 11: 987-992. [Crossref]

23. Zhang WC, Zheng XJ, Du LJ, Sun JY, Shen ZX, et al. (2015) High salt primes a specific activation state of macrophages, $\mathrm{M}(\mathrm{Na})$. Cell Res 25: 893-910. [Crossref]

24. Greenwald $\mathrm{P}$ (2003) Beta-carotene and lung cancer: a lesson for future chemoprevention investigations? J Natl Cancer Inst 95: E1. [Crossref]

25. Key TJ (2011) Fruit and vegetables and cancer risk. Br J Cancer 104: 6-11. [Crossref]

26. Boffetta P, Couto E, Wichmann J, Ferrari P, Trichopoulos D, et al. (2010) Fruit and vegetable intake and overall cancer risk in the European Prospective Investigation into Cancer and Nutrition (EPIC). J Natl Cancer Inst 102: 529-537. [Crossref]

27. Wright ME, Groshong SD, Husgafvel-Pursiainen K, Genova E, Lucia MS, et al. (2010) Effects of beta-carotene supplementation on molecular markers of lung carcinogenesis in male smokers. Cancer Prev Res (Phila) 3: 745-752. [Crossref]

28. Lam TK, Gallicchio L, Lindsley K, Shiels M, Hammond E, et al. (2009) Cruciferous vegetable consumption and lung cancer risk: a systematic review. Cancer Epidemiol Biomarkers Prev 18: 184-195. [Crossref]

29. Forman D, Altman D (2004) Vitamins to prevent cancer: supplementary problems. Lancet 364: 1193-1194. [Crossref]

30. Gaascht F, Dicato M, Diederich M (2015) Coffee provides a natural multitarget pharmacopeia against the hallmarks of cancer. Genes Nutr 10: 51. [Crossref]

31. Carlsen MH, Halvorsen BL, Holte K, Bøhn SK, Dragland S, et al. (2010) The total antioxidant content of more than 3100 foods, beverages, spices, herbs and supplements used worldwide. Nutr J 9: 3. [Crossref]

32. Albanes D (1999) Beta-carotene and lung cancer: a case study. Am J Clin Nutr 69: 1345S-1350S. [Crossref]

33. Yu X, Bao Z, Zou J, Dong J (2011) Coffee consumption and risk of cancers: a metaanalysis of cohort studies. BMC Cancer 11: 96. [Crossref]

34. Clark J, You M (2006) Chemoprevention of lung cancer by tea. Mol Nutr Food Res 50: 144-151. [Crossref]

35. Mao JT, Nie WX, Tsu IH, Jin YS, Rao JY, et al. (2010) White tea extract induces apoptosis in non-small cell lung cancer cells: the role of peroxisome proliferatoractivated receptor-\{gamma $\}$ and 15-lipoxygenases. Cancer Prev Res (Phila) 3: 11321140. [Crossref]

36. Young RP, Hopkins RJ2 (2014) High dietary fiber lowers systemic inflammation: potential utility in COPD and lung cancer. Am J Med 127: e13.. [Crossref]
37. Young RP, Hopkins RJ (2014) A review of the Hispanic paradox: time to spill the beans? Eur Respir Rev 23: 439-449. [Crossref]

38. Kim SH, Chen G, King AN, Jeon CK, Christensen PJ, et al. (2012) Characterization of vitamin D receptor (VDR) in lung adenocarcinoma. Lung Cancer 77: 265-271. [Crossref]

39. Dogan I, Onen HI, Yurdakul AS, Konac E, Ozturk C, et al. (2009) Polymorphisms in the vitamin D receptor gene and risk of lung cancer. Med Sci Monit 15: BR232-242. [Crossref]

40. Kilkkinen A, Knekt P, Heliövaara M, Rissanen H, Marniemi J, et al. (2008) Vitamin D status and the risk of lung cancer: a cohort study in Finland. Cancer Epidemiol Biomarkers Prev 17: 3274-3278. [Crossref]

41. Weinstein SJ, Yu K, Horst RL, Parisi D, Virtamo J, et al. (2011) Serum 25-hydroxyvitamin $\mathrm{D}$ and risk of lung cancer in male smokers: a nested case-control study. PLoS One 6: e20796. [Crossref]

42. Shu L, Cheung KL, Khor TO, Chen C, Kong AN (2010) Phytochemicals: cance chemoprevention and suppression of tumor onset and metastasis. Cancer Metastasis Rev 29: 483-502. [Crossref]

43. Teiten MH, Eifes S, Dicato M, Diederich M (2010) Curcumin-the paradigm of a multitarget natural compound with applications in cancer prevention and treatment. Toxins (Basel) 2: 128-162. [Crossref]

44. Kim MO, Lee MH, Oi N, Kim SH, Bae KB, et al. (2014) [6]-shogaol inhibits growth and induces apoptosis of non-small cell lung cancer cells by directly regulating Akt1/2. Carcinogenesis 35: 683-691. [Crossref]

45. Kendel M, Wielgosz-Collin G, Bertrand S, Roussakis C, Bourgougnon N, et al. (2015) Lipid composition, fatty acids and sterols in the seaweeds Ulva armoricana, and Solieria chordalis from Brittany (France): an analysis from nutritional, chemotaxonomic, and antiproliferative activity perspectives. Mar Drugs 13: 5606-5628. [Crossref]

46. Hsia TC, Liu WH, Qiu WW, et al. (2014) Maslinic acid induces mitochondria apoptosis and suppresses HIF-1a expression in A549 lung cancer cells under normoxic and hypoxic conditions. Molecules 19: 19892-19906. [Crossref]

47. Cichello SA, Yao Q, Dowell A, Leury B, He XQ (2015) Proliferative and Inhibitory Activity of Siberian ginseng (Eleutherococcus senticosus) Extract on Cancer Cell Lines; A-549, XWLC-05, HCT-116, CNE and Beas-2b. Asian Pac J Cancer Prev 16: 4781-4786. [Crossref]

48. Kwak Y, Ju J (2015) Inhibitory activities of Perilla frutescens britton leaf extract agains the growth, migration, and adhesion of human cancer cells. Nutr Res Pract 9: 11-16. [Crossref]

49. Hamaidia M, Barez PY, Carpentier A, et al. (2016) From Valeriana officinalis to cancer therapy: the success of a bio-sourced compound. Biotechnol Agron Soc Environ 20(S).

50. Emoto M. The hidden messages in water. Beyond Words Publishing, Inc., Hillsboro, Oregon, USA, 2005.

Copyright: (C2017 Ciobanu LD. This is an open-access article distributed under the terms of the Creative Commons Attribution License, which permits unrestricted use, distribution, and reproduction in any medium, provided the original author and source are credited. 